\title{
Histology and Mucous Histochemistry of the Integument and Body Wall of a Marine Polychaete Worm, Ophryotrocha n. sp. (Annelida: Dorvilleidae) Associated with Steelhead Trout Cage Sites on the South Coast of Newfoundland
}

\author{
H. M. Murray, ${ }^{1}$ D. Gallardi, ${ }^{1,2}$ Y. S. Gidge, ${ }^{1,3}$ and G. L. Sheppard ${ }^{1}$ \\ ${ }^{1}$ Fisheries and Oceans Canada, 80 White Hills Road, P.O. Box 5667, St. John's, NL, Canada A1C 5X1 \\ ${ }^{2}$ School of Fisheries, Marine Institute of Memorial University of Newfoundland, St. John's, NL, Canada A1C 5R3 \\ ${ }^{3}$ Department of Environmental Science, Memorial University of Newfoundland, St. John's, NL, Canada A1C 5S7
}

Correspondence should be addressed to H. M. Murray, harry.murray@dfo-mpo.gc.ca

Received 15 December 2011; Revised 18 January 2012; Accepted 18 January 2012

Academic Editor: Garth L. Fletcher

Copyright (c) 2012 H. M. Murray et al. This is an open access article distributed under the Creative Commons Attribution License, which permits unrestricted use, distribution, and reproduction in any medium, provided the original work is properly cited.

\begin{abstract}
Histology and mucous histochemistry of the integument and body wall of a marine polychaete worm, Ophryotrocha n. sp. (Annelida: Dorvilleidae) associated with Steelhead trout cage sites on the south coast of Newfoundland. A new species of polychaete (Ophryotrocha n. sp. (Annelida: Dorvilleidae)) was identified from sediment below Steelhead trout cages on the south coast of Newfoundland, Canada. The organisms were observed to produce a network of mucus in which groups of individuals would reside. Questions regarding the nature and cellular source of the mucus were addressed in this study. Samples of worms were taken from below cages and transported to the laboratory where individuals were fixed for histological study of the cuticle and associated mucus histochemistry. The body wall was organized into segments with an outer cuticle that stained strongly for acid mucopolysaccharides. The epidermis was thin and supported by loose fibrous connective tissue layers. Channels separating individual segments were lined with cells staining positive for Alcian blue. Mucoid cellular secretions appeared thick and viscous, strongly staining with Alcian blue and Periodic Acid Schiff Reagent. It was noted that lateral channels were connected via a second channel running through the anterior/posterior axis. The role of mucus secretion is discussed.
\end{abstract}

\section{Introduction}

The impact of aquaculture on the diversity of benthic fauna below sea cages has been well studied [1-4]. It has been observed that as the microenvironment beneath cages changes over time so does the benthic community [4]. The majority of these effects are due to excessive sedimentation resulting from feed pellets and fecal material $[1,3]$. The build-up of organic sediment can result in conditions of high sulphur content and low oxygen due to increased microbial activity within the top layers of sediment [5]. Only fauna able to tolerate low oxygen can survive under these conditions [3, 68]. It has been shown that some benthic fauna are sulfide tolerant (e.g., some polychaete species) [9-12]. Opportunistic polychaete complexes (OPCs) are frequently found beneath salmon and Steelhead trout cage sites and are considered an indicator of benthic impact related to aquaculture activities. The presence/absence of these "indicator" species or faunal groups under and around finfish aquaculture sites may show transitions from low (background) levels of organic matter to high deposition rates caused by unconsumed feed pellets and fish feces in areas subject to low transport $[8,10,12,13]$.

Intensive salmonid aquaculture on the south coast of Newfoundland and Labrador has been occurring for approximately 30 years [14]. Characteristically, aquaculture sites in this area are quite deep $(>100 \mathrm{~m})$ with hard bottoms. Recent surveys of species diversity beneath cage sites in this region have shown the occurrence of large assemblages of polychaete worms (unpublished data). Samples taken from these assemblages have indicated that the worms present are a new species, Ophryotrocha n. sp. of the Annelid family 
Dorvilleidae (G. Pohle and H. Wiklund, personal communication). Generally, Ophryotrocha sp. are small opportunistic polychaete worms of the Annelid family Dorvilleidae. Thornhill et al. [15] provide an excellent description of the basic life history traits of this genus. They typically exhibit a rounded or blunt prostomium and distinct setigers. The jaws have been noted as one of the most interesting characteristics of this group and are most commonly described at $P$ type. They are commonly found in soft sediments associated with polluted and nutrient rich habitats such as harbours and appear to graze on a variety of food types found in the substrate (e.g., bacteria, eukaryotic microbes, and detritus) $[15,16]$. While relatively low population densities have been noted in some commonly studied species, others are opportunistic or stress tolerant and can reach high abundance in environments that can be inhibitory to other organisms [15]. Some of these habitats include whalefalls and the organic rich environments beneath salmonid aquaculture cage sites [17].

While little is currently known of the basic biology of this new species of Ophryotrocha and its role in the ecology of the environment below aquaculture cages, some preliminary field and laboratory observations have shown that they produce and frequently reside in mucus complexes or networks. The function of these complexes in this species and this environment is not yet clear. However, the importance of mucus production and functionality has been explored in a number of other worm species including some of the genus Ophryotrocha [15, 18]. For example, some polychaete species (i.e., Paralvinella palmiformis) resident near deep sea hydrothermal vents have been noted to produce a continual secretion of mucus [19]. It was suggested that, in this species, the purpose might be to clear its body wall of particulate debris or in other related species to eliminate accumulated toxins, that is, elemental sulphur or metallothioneins [19]. In some Ophryotrocha sp. mucous has been noted to be associated with reproductive behaviour including the production of mucous-lined tubes and trails [15]. The excessive production of mucus in the Newfoundland species also suggests some physiological and/or ecological importance although that importance is not yet clear. The present study is an investigation designed to characterize the histology of the integument and body wall, identify sources of mucus production, and describe the distribution of mucus secreting cells in Ophryotrocha n. sp. and provide some preliminary data on the chemistry of the mucus secretions through histochemical staining. This data will help to develop our understanding of the role of this species in the microenvironment beneath salmonid aquaculture cages.

\section{Materials and Methods}

2.1. Field Sampling. Polychaetes were collected at an active steelhead trout aquaculture site (Margery Cove; $47.047^{\circ} \mathrm{N}$, $-055.411^{\circ} \mathrm{W}$ ) located near St. Alban's, Newfoundland during November 26, 2010. The polychaetes were sampled by dragging a small modified egg net $(45 \mathrm{~cm}$ by $30 \mathrm{~cm}$ oval opening reinforced with metal tubing weighted with two
$1.0 \mathrm{~kg}$ lead bullet weights; mesh size of $500 \mu \mathrm{m}$ ) over the bottom at a depth of $50 \mathrm{~m}$. The net was deployed by hand tossing it at horizontal distances of $10-15 \mathrm{~m}$ in various directions from the vessel, predominately in areas located between aquaculture cages. Once the net settled to the expected depth it was slowly dragged along the bottom and subsequently hauled aboard the vessel. The net was then inverted inside a $20 \mathrm{~L}$ bucket filled with seawater collected at a depth of $20 \mathrm{~m}$ using a small Niskin bottle. For transport back to the laboratory (Northwest Atlantic Fisheries Centre, St. John's, NL), worms were stored in coolers containing freshly collected seawater from an appropriate depth. On average, roughly 100 polychaetes were collected during each net deployment. Samples were largely free of debris or mud which suggested the net sampled the top layer of the bottom as intended. After arrival at the laboratory polychaetes were transferred to $4 \mathrm{~L}$ plastic containers partially filled with sand and seawater (water temperature $=3-4^{\circ} \mathrm{C}$ ). The containers holding worms were subsequently put in a second holding tank filled with sand filtered chilled water (water temperature $=$ $3-4^{\circ} \mathrm{C}$ ) and air stones were added to provide aeration. The water flow into each tank allowed for approximately one turnover per hour. The oxygen saturation on average was between 90 and $95 \%$. Aluminum foil was placed over each individual container to reduce light exposure. Crushed trout feed was added to each container as a potential food source. Worms were kept under the above conditions for one month prior to tissue sampling for histology and mucus histochemistry.

2.2. Histology. Groups of five to ten worms were fixed in $10 \%$ neutral buffered formalin for 24 to $48 \mathrm{hrs}$ at $4^{\circ} \mathrm{C}$. Following fixation the samples were dehydrated through ethanol series, cleared in two changes of xylene, and infiltrated and embedded in paraffin for both longitudinal and transverse sections. Six to eight micron sections were cut using a rotary microtome (Leica, RM2265), placed on uncoated glass slides, dried overnight at $37^{\circ} \mathrm{C}$, and stored at room temperature. Sections were stained with either haematoxylin and eosin (H\&E) or Alcian blue (AB) pH 2.5 and Periodic Acid Schiff's reagent (PAS) [20]. Slides were stained in batches using a Leica, Auto Stainer XL and were examined using a Zeiss Axio Imager-A1 compound microscope with attached AxioCam HRc camera and associated software. Image plates were created using Photoshop Elements 7.0.

\section{Results}

Within hours of transfer to the holding containers the worms were noted to produce copious amounts of a clear mucus-like substance. Frequently, groups of individuals were observed to be suspended in networks of mucus situated just off the tank bottom normally in areas associated with added intact food pellets (Figure 1(a)).

Individuals were observed to be pink to red in colour with a mean length of $10.25 \mathrm{~mm}(n=50)$ and a mean mass of $12.8 \mathrm{mg}(n=50)$ (Figures 1(a) and 1(b)). Morphologically, they were divided into approximately 36 segments with defined parapodia and chaetae (Figure 1(b)). The anterior 


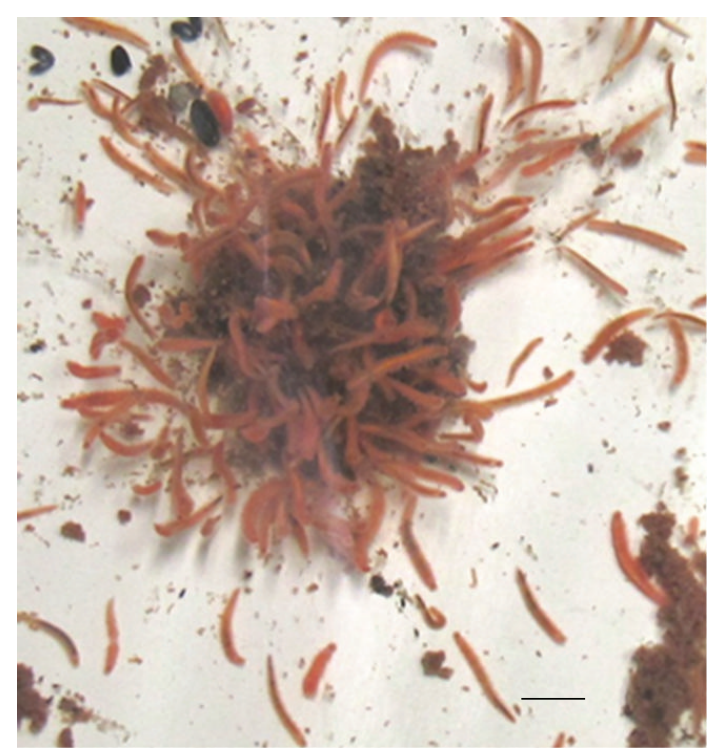

(a)

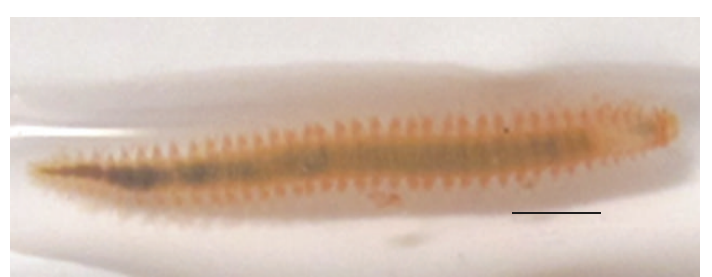

(b)

FIGURE 1: General appearance and size of polychaetes (Ophyrotrocha sp.) from salmonid aquaculture sites located on the south coast of Newfoundland. (a) Congregation of worms in mucus complex around food pellet in the laboratory tanks (scale bar $=8 \mathrm{~mm}$ ). (b) Worm showing upper size range of individuals (approx. $16 \mathrm{~mm})($ scale bar $=2 \mathrm{~mm})$.

region exhibited two peristomal achaetous segments with jaw (Figure 1(b)). Longitudinal histological sections through the body indicated that each segment was defined by a single pair of parapodia supported internally with a club-shaped muscular structure surrounding one to two chaetae (Figure 2(a)). Each segment adjacent to the parapodia was defined by a narrow channel lined with a single layer of cells. Generally the secretory cells were cuboidal with a basal nucleus and eosinophilic apical cytoplasm (Figure 2(d)). This epithelium seemed to be continuous with the integumental surface of the parapodia (Figures 2(a) and 2(b)). The luminal surface adjacent to parapodia was coated by a relatively thin layer of mucoid secretion (Figures 2(a) and 2(b)). Near the anterior region of the worm, other tubular structures appeared to produce a thicker or more viscous layer of mucus (Figures 2(c) and $2(\mathrm{~d}))$. It is unclear as to whether these regions are associated with the previously mentioned channels or represent another type of secretory structure.

Histochemical staining of longitudinal sections through the body wall with Alcian Blue ( $\mathrm{pH}$ 2.5) and PAS showed that the outer portion of the integument was distinctly Alcian blue positive as was a layer of connective tissue immediately below (Figures 3(a), 3(b), and 3(c)). The total thickness of the outer integumental layer was approximately 0.5 to $1 \mu \mathrm{m}$. Each body segment was defined by large PAS positive muscle blocks lying just adjacent to the integument (Figures 3(a) and 3(b)). Interestingly, no distinct cellular integumental epidermis was discernable following histochemical staining. The outer cuticular region also stained strongly with Alcian blue but showed no evidence of distinct secretory cells (Figure 3(e)). Channels separating individual segments were lined with cells staining slightly positive for Alcian blue
(Figures 3(c) and 3(d)). Mucoid cellular secretions appeared thick and viscous, strongly staining with Alcian blue and PAS (Figures 3(c), 3(d), and 3(f)). It was also noted that lateral channels were connected via a second channel running through the anterior/posterior axis (Figure 3(b)). The point of connection appeared to form a small collecting sinus (Figure 3(b)).

\section{Discussion}

Samples for the present study were collected near the end of the annual production cycle for steelhead trout on the south coast of Newfoundland so the introduction of organic material would have gone through maximum input. Visual sampling revealed that the worms appear to reside in mucus complexes associated with this organic layer. This behaviour was subsequently verified through tank observations. The production of mucus in this species appears significant to its basic ecology and warranted further investigation. Individuals from the present study appeared most similar morphologically to Ophryotrocha craigsmithi, originally described from both a Minke whale carcass and sediment collected from below a fish farm in Norway [17]. Histology was not discussed in the original description of O. craigsmithi and no mention was made of mucus secretion. The information provided in the present study is a first description of the basic histology and mucous histochemistry of the integument in a new species of Ophyrotrocha found to congregate below salmonid aquaculture sites on the south coast of Newfoundland.

Histochemical staining using Alcian blue $\mathrm{pH} 2.5$ and Period Acid/Schiff reagent provided a comprehensive view of tissue diversity in histological sections in the current study. 


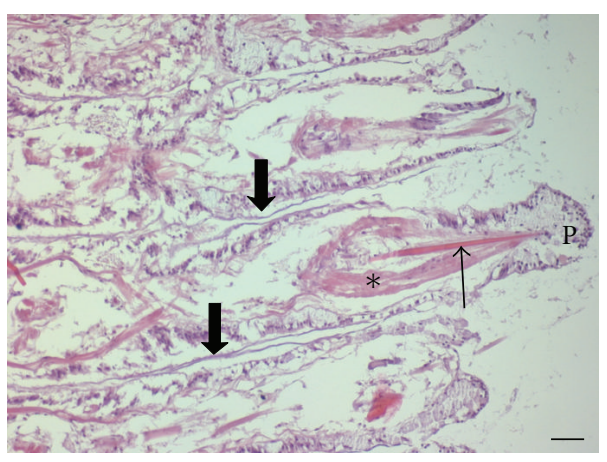

(a)

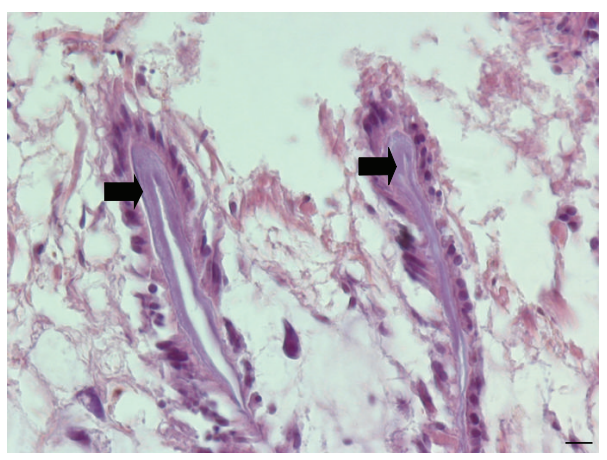

(c)

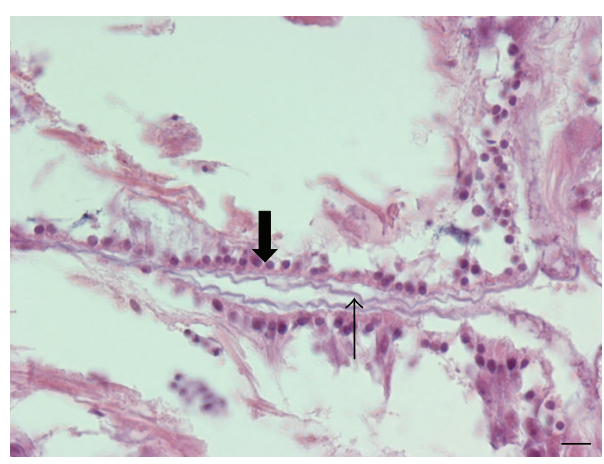

(b)

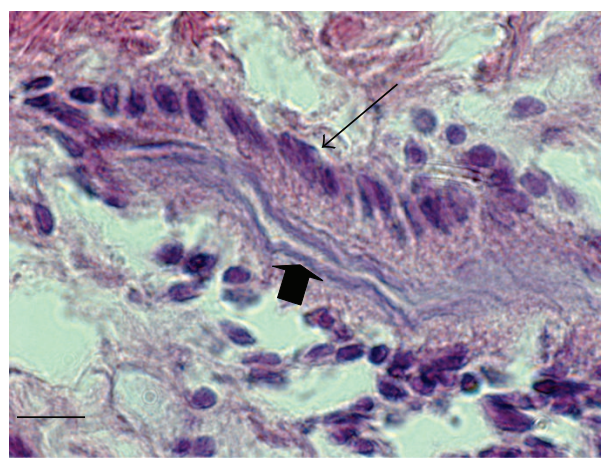

(d)

Figure 2: Histology of the integument of Newfoundland Ophryotrocha sp. (a) Overview of the epidermis and cuticle showing detail of parapodia (note muscular support structure (asterisk) and chaeta (thin arrow)) and orientation of mucus channels. Thick arrows indicate a thin layer of mucus (scale bar $=5 \mu \mathrm{m}$ ). (b) Detail of mucus channel showing secretory cells with basal nuclei and eosinophilic apical cytoplasm (thick arrow). Note thin mucoid secretion on the luminal surface of cells lining channel (thin arrow) (scale bare $=1 \mu \mathrm{m})$. (c) Detail of mucus channel from anterior portion of worm. Note the presence of a more viscous mucoid secretion (thick arrows) in this region compared to the previous (Scale bar $=1 \mu \mathrm{m}$ ). (d) Detail of cells lining anterior glandular structure. Note basal nucleus and granular apical cytoplasm (large arrow) with associated viscous secretion (arrowhead) (scale bar $=1 \mu \mathrm{m}$ ).

The outer most region of the integument (cuticle) stained strongly with Alcian blue suggesting a high content of acid mucopolysaccaride but did not show identifiable secretory cells. Surface mucus secretion was not noted in this region and may suggest that the fixation was not effective enough to preserve mucus on the outer integumental surface. Interestingly, mucus secretion was localized to defined channels that appeared to run perpendicular to each other forming what seemed to be collection sinuses at points of intersection in longitudinal orientation. Hausen [21] indicated that secretory cells release their contents via pores in the cuticle. This was not directly evident in this investigation and suggests that the observation of cell lined secretory channels in this species may be a unique character and a first description.

Histologically, within the species from the current study, cells lining secretion channels would sometimes appear continuous with the cuticular/epidermal region or alternatively not appear to gain access to the cuticle at all. Any mucus production would then potentially be secreted directly to the outer integument through the channels. This secretion could then be used as a low friction surface for locomotion or as observed in the laboratory, as a mesh or net structure. It is not clear as to the function of the mucous mesh but one could hypothesize that it may be used as a way of providing colonial cohesiveness, particle trapping, and/or a reproductive role. It is interesting to note that in histological section occasionally the mucoid secretions would appear to vary in volume and apparent viscosity. This may be an indicator of variable function. Further work will be necessary to elucidate the respective roles of this secretion in this species.

Mucus production has been investigated in other species of polychaete and has been noted to have a number of functions related to physiology and ecology [21]. In some species mucous secretions are used for maintaining a film on the body surface or in the production of mucus feeding traps and transport of food particles to the mouth [22, 23]. In other species it has been noted to be utilized in the production of brood chambers or egg cases and in the lining of burrows or tubes [21].

The cellular source of mucus secretion is variable and can be species-specific. Generally, cells localized to the epidermis and the cuticles are found to be associated with the majority of the mucus production in polychaetes [21]. Numerous studies have investigated the relationship between structure and function in this tissue using a variety of techniques including ultrastructural, histological, and histochemical 


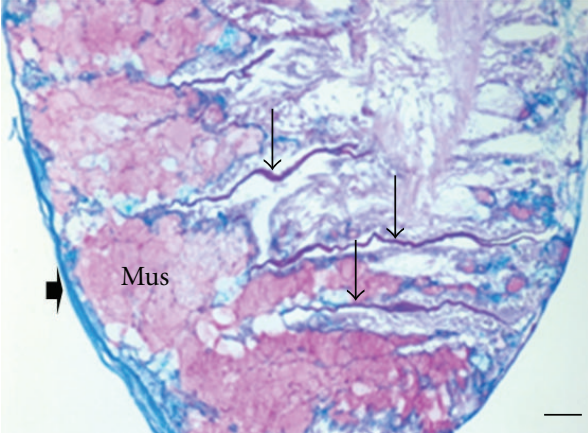

(a)

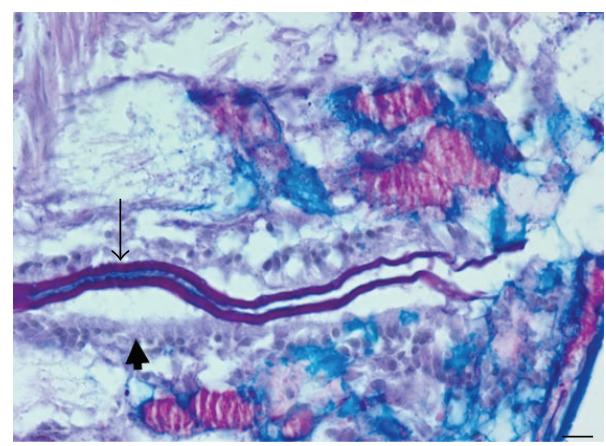

(c)

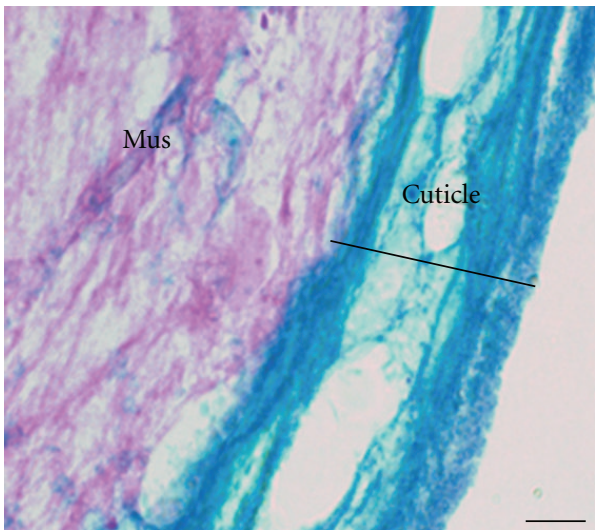

(e)

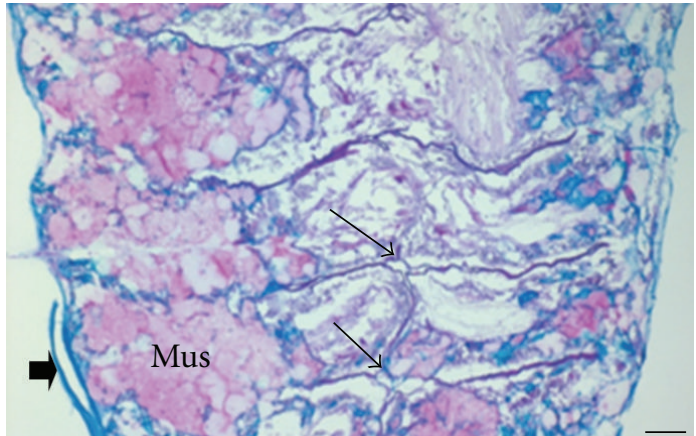

(b)

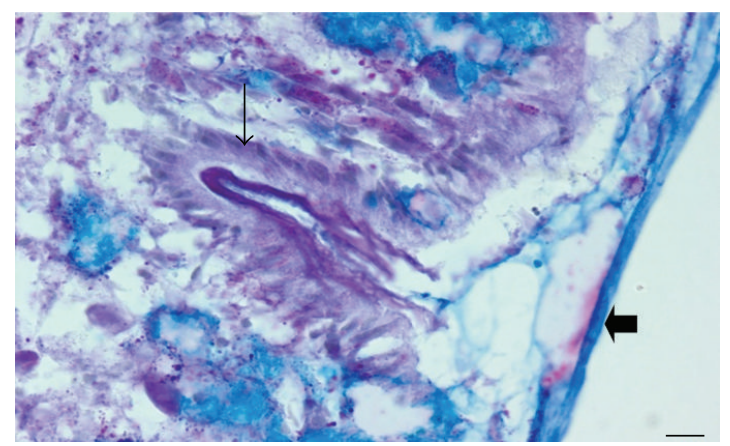

(d)

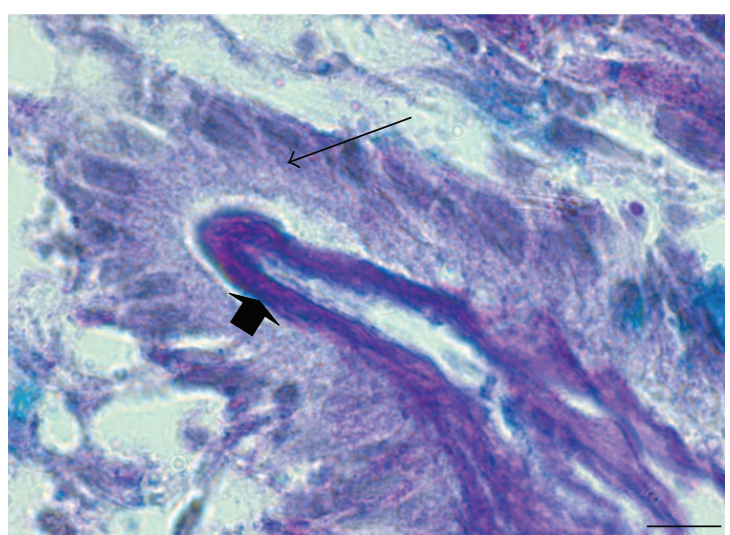

(f)

Figure 3: Alcian blue ( $\mathrm{pH}$ 2.5)/PAS staining of longitudinal sections cut through the body wall showing segmental muscle blocks (mus) with detail of adjacent mucus channels. (a) Low magnification of a histological section through the worm showing latero-lateral orientation of mucus channels (thin arrows). Note also the strong Alcian blue ( $\mathrm{pH} 2.5)$ reaction in the cuticle (arrowhead) (Scale bar $=5 \mu \mathrm{m}) .(\mathrm{b})$ Low magnification of a histological section through the worm showing anterior/posterior orientation of channels perpendicular to laterals. Note presence of collection sinuses at channel intersections (thin arrows). The cuticle again stained strongly with Alcian blue (arrowhead) (Scale bar $=5 \mu \mathrm{m}$ ). (c) High magnification of lateral mucus channel showing intense staining of secretion with Alcian blue (pH 2.5)/PAS (large arrow). Note lightly stained secretory cells with basal nuclei lining the channel (arrowhead) (Scale bar $=1 \mu \mathrm{m})$. (d) High magnification of lateral mucus channel opening toward the integumental surface. Note secretory cells with basal nuclei (small arrow) and deeply stained mucoid secretion (large arrow). The cuticle is indicated by the arrowhead (Scale bar $=1 \mu \mathrm{m}$ ). (e) High magnification of outer cuticle adjacent to a muscle block (Mus) showing strong Alcian blue reactivity in the region (Scale bar $=1 \mu \mathrm{m}$ ). (f) Detail of glandular structure showing secretory cells exhibiting basal nucleus and granular apical cytoplasm (large arrow). Note viscous secretion associated with the luminal surface (arrowhead). (Scale bar $=1 \mu \mathrm{m})$.

analysis (reviewed in [21]). The structure of the cuticle in polychaetes is generally dependent on its life history and basic ecology. For example, in nontube dwelling worms the cuticle is thicker and consists of collagen fibers arranged in layers whereas tube dwellers have a thinner cuticle or none at all [24-27]. Anton-Erxleben [24] noted that the polychaete cuticle was composed of two classes of organic material, a carbohydrate component and a protein component 
(collagen). Various histochemical investigations have shown that epidermal cells can secrete many different substances, for example, glycosaminoglycans, different mucopolysaccharides, and mucoproteins $[21,26,28]$.

The orientation and organization of the mucus secreting cells from the species in this study certainly is novel, based on available literature descriptions, and warrants further investigation. In addition, observations on the utilization of the mucus in this species, both in the field and laboratory, raise further questions toward understanding its significance in the ecology and physiology of this species especially with reference to the transitional communities found beneath salmonid aquaculture sites.

\section{Acknowledgments}

This work was supported by a grant provided through the Aquaculture Collaborative Research Development Program (ACRDP) and the Department of Fisheries and Oceans Canada. The authors would like to thank Mr. Danny Ings for his many informative discussions during the progress of this project.

\section{References}

[1] R. H. Findlay, L. Watling, and L. M. Mayer, "Environmental impact of salmon net-pen culture on marine benthic communities in Maine: a case study," Estuaries, vol. 18, no. 1, pp. 145179, 1995.

[2] P. Tomassetti and S. Porrello, "Polychaetes as indicators of marine fish farm organic enrichment," Aquaculture International, vol. 13, no. 1-2, pp. 109-128, 2005.

[3] B. T. Hargrave, G. A. Phillips, L. I. Doucette et al., "Assessing benthic impacts of organic enrichment from marine aquaculture," Water, Air, and Soil Pollution, vol. 99, no. 1-4, pp. 641650, 1997.

[4] H. Yokoyama, K. Abo, and Y. Ishihi, "Quantifying aquaculture-derived organic matter in the sediment in and around a coastal fish farm using stable carbon and nitrogen isotope ratios," Aquaculture, vol. 254, no. 1-4, pp. 411-425, 2006.

[5] D. J. Wildish and G. W. Pohle, "Benthic macrofauna changes resulting from finfish mariculture," in The Handbook of Environmental Chemistry. Part M Environmental Effects of Marine Finfish Aquaculture, B. T. Hargrave, Ed., vol. 5, pp. 275-304, Springer, Berlin, Germany, 2005.

[6] R. J. Diaz and R. Rosenberg, "Marine benthic hypoxia: a review of its ecological effects and the behavioural responses of benthic macrofauna," Oceanography and Marine Biology, vol. 33, pp. 245-303, 1995.

[7] H. C. Nilsson and R. Rosenberg, "Succession in marine benthic habitats and fauna in response to oxygen deficiency: analysed by sediment profile-imaging and by grab samples," Marine Ecology Progress Series, vol. 197, pp. 139-149, 2000.

[8] K. M. Brooks, "Evaluation of the relationship between salmon farm biomass, organic inputs to sediments, physicochemical changes associated with the inputs, and the infaunal response-with emphasis on total sediment sulfides, total volatile solids, and oxygen reduction potential as surrogate end-points for biological monitoring," Report to the Technical Advisory Group, BC Ministry of the Environment, pp.183, 2080A Labieux, Road, Nanaimo, Canada V9T 6J9, 2001.
[9] B. T. Hargrave, D. E. Duplisea, E. Pfeiffer, and D. J. Wildish, "Seasonal changes in benthic fluxes of dissolved oxygen and ammonium associated with marine cultured Atlantic salmon," Marine Ecology Progress Series, vol. 96, no. 3, pp. 249-257, 1993.

[10] P. Pocklington, D. B. Scott, C. T. Schaffer et al., "Polychaete response to different aquaculture activities," in Proceedings of the Actes de la erne Conference Internationale des Polychetes Mem Mus Natn 'ist Nat, J. C. Dauvin, L. Laubier, and D. J. Reish, Eds., pp. 511-520, 1994.

[11] D. E. Duplisea and B. T. Hargrave, "Response of meiobenthic size-structure, biomass and respiration to sediment organic enrichment," Hydrobiologia, vol. 339, no. 1-3, pp. 161-170, 1996.

[12] H. K. Dean, "The use of polychaetes (Annelida) as indicator species of marine pollution: a review," Revista de Biologia Tropical, vol. 56, supplement 4, pp. 11-38, 2008.

[13] D. P. Weston, "Quantitative examination of macrobenthic community changes along an organic enrichment gradient," Marine Ecology Progressive Series, vol. 61, pp. 233-244, 1990.

[14] M. F. Tlusty, V. A. Pepper, and M. R. Anderson, "Realizing the potential of frontier regions in aquaculture-the newfoundland salmonid experience," World Aquaculture, vol. 31, pp. 50-54, 2000.

[15] D. J Thornhill, T. G. Dahlgren, K. M. Halanych et al., "Evolution and ecology of Ophryotrocha (Dorvilleidae, Eunicida)," in Annelids in Modern Biology, D. H. Shain, Ed., pp. 242-252, John Wiley \& Sons, 2009.

[16] T. G. Dahlgren, B. Åkesson, C. Schander, K. M. Halanych, and P. Sundberg, "Molecular phylogeny of the model annelid Ophryotrocha," Biological Bulletin, vol. 201, no. 2, pp. 193-203, 2001.

[17] H. Wiklund, A. G. Glover, and T. G. Dahlgren, "Three new species of Ophryotrocha (Annelida: Dorvilleidae) from a whale-fall in the North-East Atlantic," Zootaxa, no. 2228, pp. 43-56, 2009.

[18] V. Storch, "The ultrastructure of polychaeta. I. Integument," in Microfauna Marina, W. Westheide and C. O. Hermans, Eds., vol. 4, pp. 13-36, Verlag, Stuttgart, Germany, 1988.

[19] K. Alain, M. Olagnon, D. Desbruyères et al., "Phylogenetic characterization of the bacterial assemblage associated with mucous secretions of the hydrothermal vent polychaete Paralvinella palmiformis," FEMS Microbiology Ecology, vol. 42, no. 3, pp. 463-476, 2002.

[20] J. D. Bancroft and H. C. Cook, Manual of Histological Techniques, Longman Group Limited, New York, NY, USA, 1984.

[21] H. Hausen, "Comparative structure of the epidermis in polychaetes (Annelida)," Hydrobiologia, vol. 535, no. 1, pp. 2535, 2005.

[22] N. McDaniel and K. Banse, "A novel method of suspension feeding by the maldanid polychaete Praxillura maculata," Marine Biology, vol. 55, no. 2, pp. 129-132, 1979.

[23] P. R. Flood and A. Fiala-Médioni, "Structure of the mucous feeding filter of Chaetopterus variopedatus (Polychaeta)," Marine Biology, vol. 72, no. 1, pp. 27-33, 1982.

[24] F. Anton-Erxleben, "Investigations on the cuticle of the polychaete elytra using energy dispersive X-ray analysis," Helgoländer Meeresuntersuchungen, vol. 34, no. 4, pp. 439-450, 1981.

[25] L. M. Gustavsson and C. Erséus, "Cuticular ultrastructure in some marine oligochaetes (Tubificidae)," Invertebrate Biology, vol. 119, no. 2, pp. 152-166, 2000.

[26] L. M. Gustavsson, "A Comparative study of the cuticle in some aquatic oligochaetes (Annelida: Clitellata)," Journal of Morphology, vol. 248, no. 2, pp. 185-195, 2000. 
[27] M. Mastrodonato, E. Lepore, M. Gherardi, S. Zizza, M. Sciscioli, and D. Ferri, "Histochemical and ultrastructural analysis of the epidermal gland cells of Branchiomma luctuosum (Polychaeta, Sabellidae)," Invertebrate Biology, vol. 124, no. 4, pp. 303-309, 2005.

[28] A. Licata, A. Mauceri, L. Ainis et al., "Lectin histochemistry of epidermal glandular cells in the earthworm Lumbricus terrestris (Annelida Oligochaeta)," European Journal of Histochemistry, vol. 46, no. 2, pp. 173-178, 2002. 

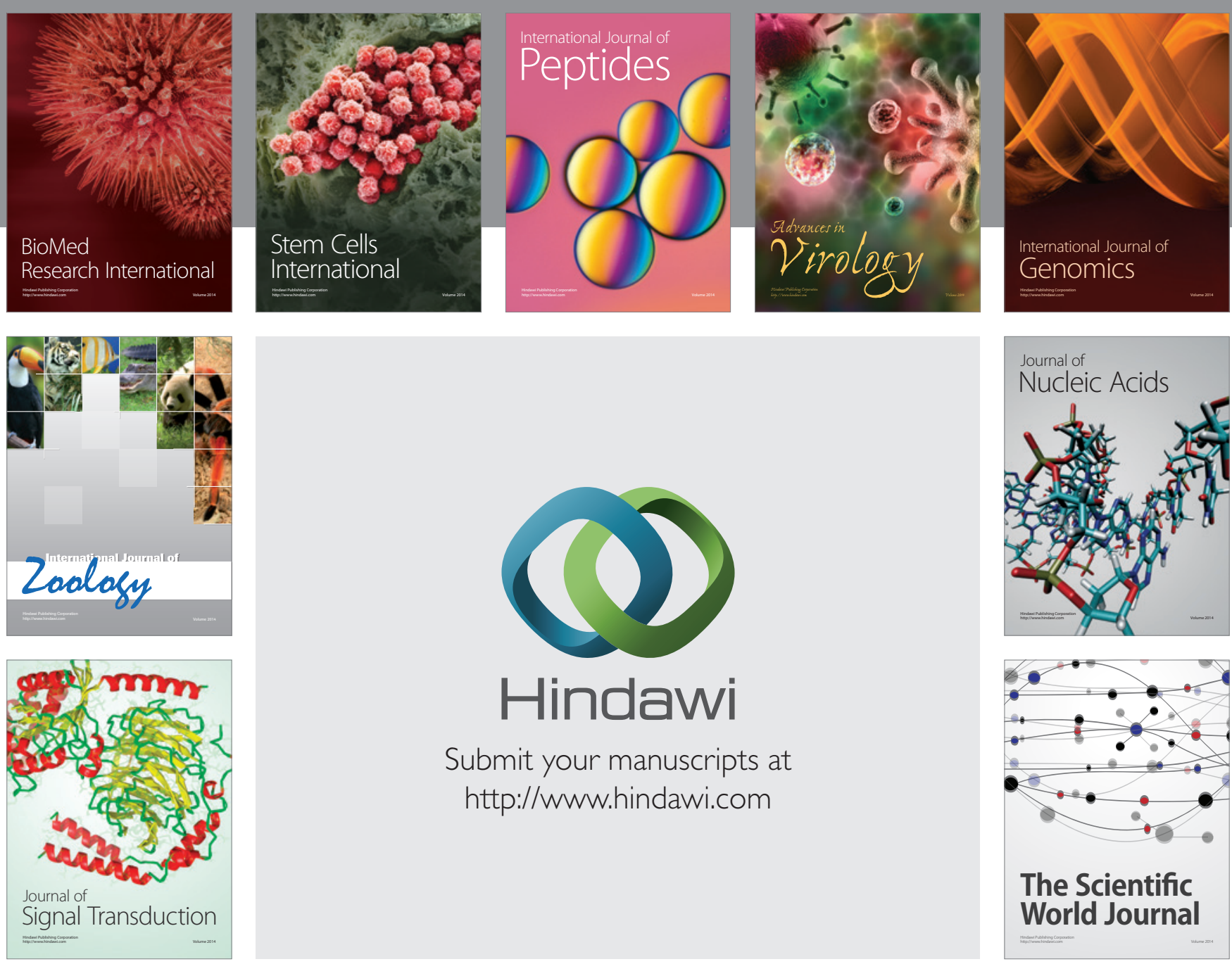

Submit your manuscripts at

http://www.hindawi.com
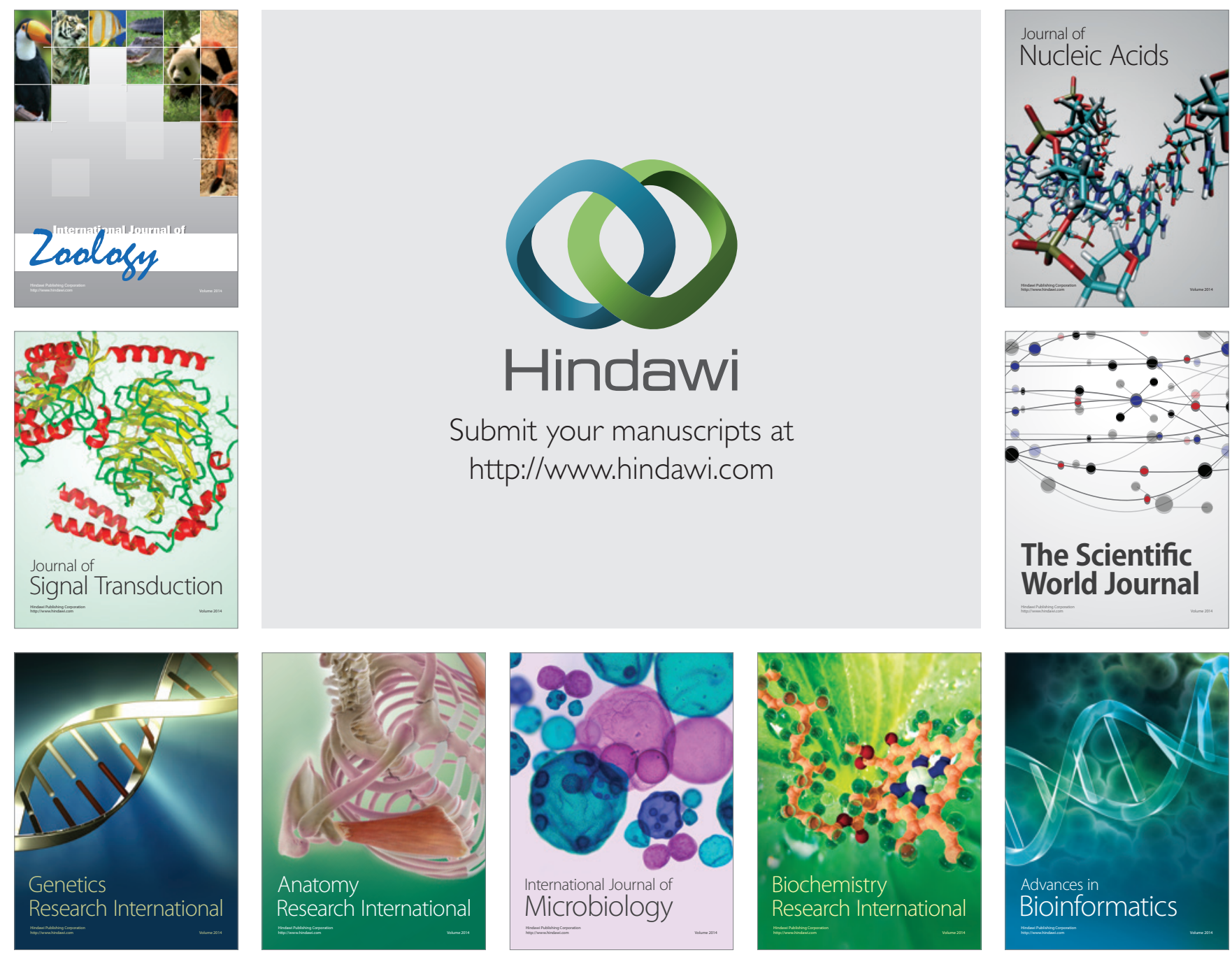

The Scientific World Journal
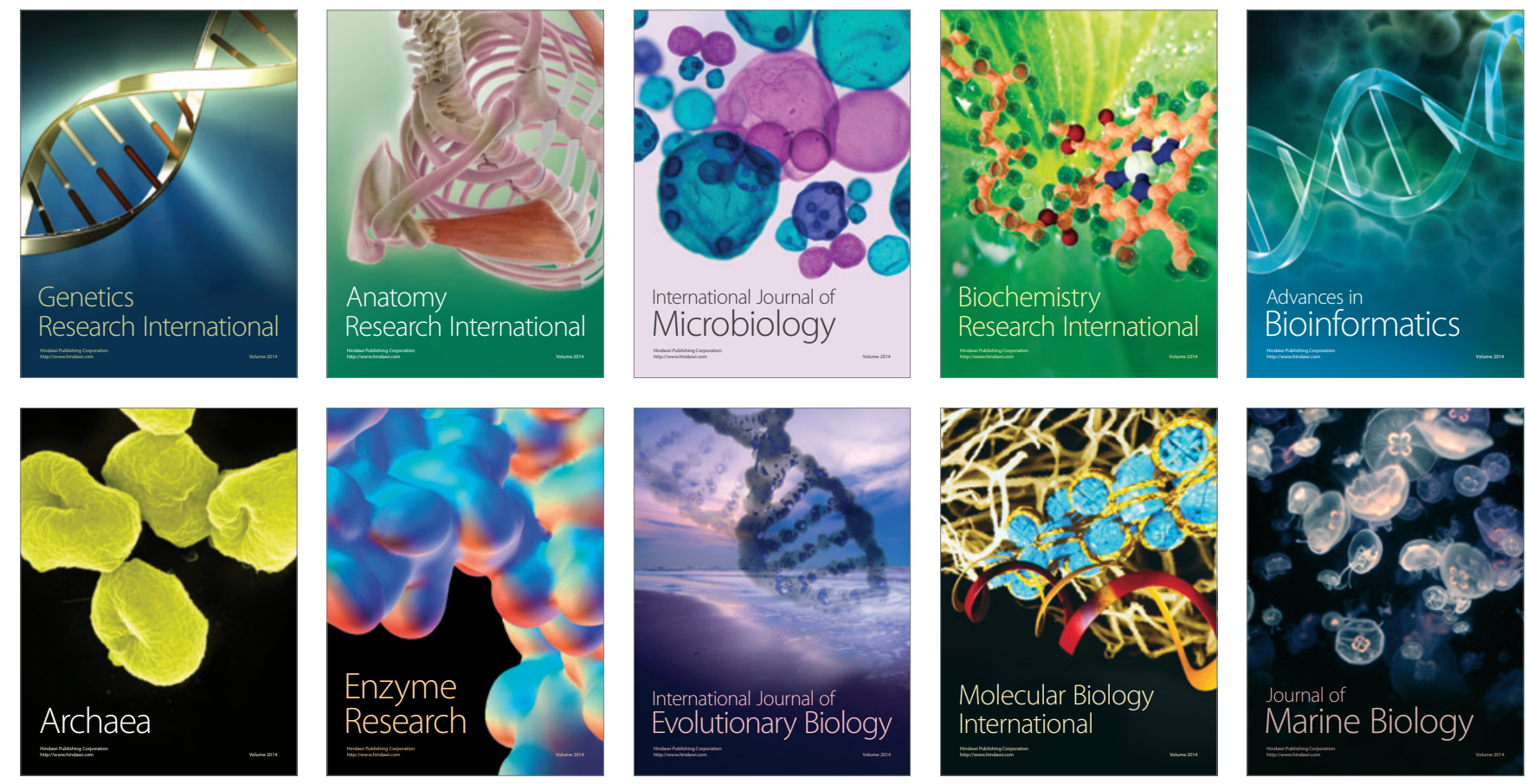